\title{
Prevalence and determinants of tension headache among medical students during their clinical years at King Abdulaziz University in Jeddah, 2019
}

\author{
Weam Nabeel Qutub ${ }^{1 *}$, Reham Shakir Magharbel ${ }^{2}$, Salma Walid Adham ${ }^{3}$, Wedad Mahmoud Bardisi ${ }^{4}$, \\ Naeema Abdulkader Akbar ${ }^{5}$
}

${ }^{1-4}$ Family Physician, ${ }^{5}$ Community Physician, ${ }^{1-4}$ The Joint Program of Postgraduate Studies of Family Medicine, Jeddah, Saudi Arabia, ${ }^{5}$ Public Health, MOH, Jedda, Saudi Arabia

*Corresponding Author: Weam Nabeel Qutub

Email: weam.qutub@gmail.com

\begin{abstract}
Background: Tension-type headache (TTH) is the most common primary headache disorder among medical students. It affects academic performance and the quality of the student's daily lives.

Objective: This study aimed to investigate the prevalence of TTH and associated factors among students at King Abdulaziz University (KAU) in Jeddah, Saudi Arabia.

Methods: A cross-sectional study involved students at KAU in the academic years from 4th to 6th grades during the calendar year of 2019. For sampling purposes, we adopted a stratified proportional random sampling technique, and for data collection, we used a selfadministered questionnaire. We defined TTH according to the diagnostic criteria in the third edition of the International Classification of Headache Disorders (ICHD-3b) from the International Headache Society (HIS).

Results: A total of 387 medical students were approached, 50.1\% were females, and $49.9 \%$ were males; their mean age was $22.8 \pm$ SD 1.4. The lifetime TTH was $43.9 \%$, and the 1 -year prevalence TTH was $28.9 \%$, these included both frequent TTH $25 \%$ and infrequent TTH $73 \%$. Only $2 \%$ suffered from chronic TTH. Female sex was an unconfounded predictor for TTH, and sleeping for less than 8 hours/night was significantly associated with TTH $(\mathrm{p}<0.05)$. The most common aggravating factors included studying stressors (83.3\%), and psychological stressors (46.5\%).

Conclusion: tension-type headache is a common problem among medical students. It is highly recommended to provide a stress-free study environment, stress management courses, and relaxation programs.
\end{abstract}

Keywords: Tension-type headache, Prevalence, Medical students, Saudi Arabia.

\section{Introduction}

Headache disorders are a significant public health concern, constituting the most common complaint among patients seeking medical care, ${ }^{1}$ and considered the most prevalent disorders of the nervous system. ${ }^{2}$ It is estimated that around half of the world population suffer from headache, ${ }^{3-5}$ often lifelong illnesses. ${ }^{6,7}$ However, pain perception changes with age, and the symptoms of headache changes during lifespan. ${ }^{8}$

Headaches may be secondary to serious medical conditions such as intracranial infections or neoplasms or maybe primary including tension-type headache (TTH), migraine, and cluster headache. ${ }^{3,4}$ Tension-type headache is the most prevailing type, with prevalence of over $40 \% ;^{3,5,9}$ however, it is the least studied headache..$^{9,10}$ The next common type of primary headache is migraine, ranging between $11-18 \%,{ }^{11,12}$ and followed by a cluster headache $(3 \%){ }^{5}$ Although primary headaches are nonfatal, they result in substantial disability, diminish productivity, and may deter social relationships and ruin a person's quality of life. It may also lead to medicationoveruse headache. ${ }^{6,7,9}$

Tension-type headache typically bilateral, a band like, pressing or tightening in quality, or dull ache, and radiates from the forehead to the occiput or the neck muscles. It can range from the occasional mild to daily disabling headache (episodic or chronic). The episodic tension-type further subdivided into two groups, the infrequent and the frequent type., ${ }^{9,13}$ On the other hand, migraine-type headache is unilateral, and include nausea, vomiting, photophobia, and phonophobia. ${ }^{3,13}$ On the contrary to migraine, routine physical activity does not exacerbate TTH $; 3$ nevertheless, all patients with frequent or severe attacks need careful evaluation to exclude any serious condition. ${ }^{13}$

On the ground that psychological and physical stressors increase during the medical curriculum, medical school students suffer from headaches more commonly than the general population. ${ }^{14,15}$ The severity of headache is significantly related to the negative impact of headache, 
which includes reduced academic performance, absenteeism and discipline failures, in addition to reduced quality of life, and increased diagnosis of comorbid psychiatric conditions. ${ }^{15,16}$

The profound demographic and epidemiological transitions worldwide which resulted in noticeable reduction in mortalities increased the relative importance of headache for public health, and warrant greater attention in health policy decisions and research resource allocation to provide stronger evidence of the need for action. ${ }^{1}$ in particular the impact of headache on medical students which is understudied despite its high prevalence. ${ }^{14}$

This study aimed to investigate the actual prevalence of TTH headaches and associated factors among medical students at King Abdul-Aziz University (KAU), the largest public university in Jeddah, SA.

\section{Materials and Methods}

This cross-sectional study involved students at KAU in the academic years from 4 th to 6th grades during the calendar year of 2019. By using a stratified proportional random sampling technique, 387 medical students were enrolled in the study. After obtaining approval letter from both the research committee of the Joint Program of Family Medicine and the Institutional Review Board (IRB) of $\mathrm{KAU}$, and after obtaining written consent from the students, a self-administered questionnaire was handed to them during their rotation at the hospital.

The internal validity and reliability of the questionnaire were tested using Cronbach's alpha test. Both medical and research experts assessed the face and content validity. The questionnaire involved three parts. The first part assessed socio-demographic characteristics, medical history, and health-related habits such as physical activities, smoking, eating, and sleeping habits. The second part inquired about the headache profile, designed to comply with International Classification of Headache Disorders - third edition (ICHD-3b) from the International Headache Society (HIS), ${ }^{13}$ and the third part comprised questions about factors that aggravate or relieve headache, headache management and impact of headache on the student's achievement such as Grade Point Average (GPA).

Tension-type headache was defined as a student who had experienced ten or more attacks of headache (criterion A) during the past year, and which had lasted for at least 30 minutes to 7 days each (criterion B). The headache accompanied by at least two of the following four pain characteristics: bilateral location, non-pulsating (pressing or tightening), mild-to-moderate severity, and not aggravated by routine physical activity (criterion C), in the absence of features that characterize migraine, such as nausea, vomiting, photophobia, and phonophobia, but could include either photophobia or photophobia, but not both (criterion D). Besides, the headache was not attributed to other disorders (criterion E). ${ }^{13,17}$ Chronic TTH defined as a headache that lasts for more than 15 days/ month (for more than six months) and fulfilling all the criteria for TTH. While Episodic TTH further subclassified into Infrequent and frequent tension-type headache. Infrequent TTH defined as headache of at least ten episodes occurring fewer than one day per month on average (fewer than 12 days/year) and fulfilling all the criteria for TTH, and Frequent TTH defined as headache of at least ten episodes occurring on more than one but fewer than 15 days/ month for (less than six months) at least three month and fulfilling all the criteria for TTH. ${ }^{3,13}$ Life-long TTH was assessed as headache fulfilling all the criteria for TTH during a lifetime but not applying the diagnostic criterion $\mathrm{A}$ (at least ten episodes of headache). ${ }^{18}$

\section{Statistics}

Descriptive statistics were conducted in terms of frequency (n) and proportions (\%). Bivariate analyses (Pearson chi-square tests with Yates' correction for continuity when a $2 \times 2$ table) performed to study the association between the 1-year prevalence TTH (Y/N) and sociodemographic and health-related covariates. The unconfounded effect of the predictors assessed using multivariable logistic regression and included in the model factors that were significantly associated with the one-year prevalence TTH from the bivariate analyses, and factors that are known causes of the TTH, based on knowledge of the existing literature. Enter method was the model used for building up the Logistic regression model. The model included the following predictors; Gender, Age, family income, having a chronic illness, having daily morning breakfast, performing physical activities, stress level, and sleeping hours. The likelihood ratio, score, and Wald tests used to evaluate the overall model. Significant results of $\mathrm{p}<0.05$ indicated that the model was more effective than the null model and that all observations predicted to belong in the largest outcome category. HosmerLemeshow (The goodness-of-fit test) yielded a $\chi 2(8)$ of 7.278 and was insignificant $(\mathrm{p}=0.507)$, indicating that the 
model was well-fitting to the data (Table 4). Statistical significance defined at the $5 \%$ level, and analyses were all carried out using IBM SPSS Statistics V.20 for Mac.

\section{Results}

\section{Demographics}

A total of 387 medical students were approached, 50.1\% were females, and $49.9 \%$ were males, their ages ranged from 20 to 36 years, and only $7 \%$ were married. More than half of them had family income more than 15000 SR; fourth grade level constituted $39.0 \%$ of the students, followed by 5 th grade $(34.1 \%)$ and 6 th grade $(26.9 \%)$ (Table 1).

Description of health-related characteristic of the students are summarized in table 2. More than one-third of the students do not perform any physical activity, while only $19.1 \%$ have regular body exercise, and less than one third $(23.8 \%)$ used to have daily breakfast. The bulk $(81.9 \%)$ were non-smokers, but the majority of them drink coffee regularly, mostly once per day (39.3\%), however energy drink was minimal. Only one third declared sleeping problem, although only one third slept for a minimum of 8 hours/night (31.8\%). Only 57 (14.7\%) students were suffering from chronic illness, and they suffered from varying degrees of stress; however, most of them $(66.9 \%)$ were capable of managing their stress.

\section{Prevalence of TTH}

The lifetime prevalence of headache was $66.4 \%$ (257 students), while lifetime TTH (not including criterion A of ICHD-3b) was 43.9\% (170 students). One-year prevalence of TTH (including criterion A through $\mathrm{E}$ of ICHD-3b) was $28.9 \%$ (112 students), these included both frequent TTH $25 \%$ (28 students) and infrequent TTH $73 \%$ (82 students). Only $1.8 \%$ ( 2 students) met the criteria for chronic TTH (Fig. 1).

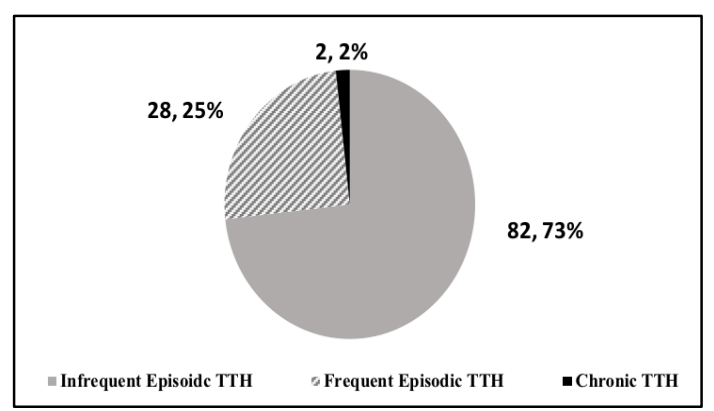

Fig. 1: Tension-type headache among medical school students

\section{Covariates}

In the univariate analyses (Table 3), only the gender of the students found related to $\mathrm{TTH}$, as females were significantly at higher risk of TTH $(\chi 2: 4.88$, P-value 0.027 ). Although generally sleeping trouble was not different between students with and without TTH, there was a significant difference in respect to sleeping hours, as sleeping for less than 8 hours/night was associated with a higher rate of TTH $(\chi 2: 9.20, \mathrm{P}=0.002)$. None of the other health-related characteristics, namely having a chronic illness, performing physical activities, smoking, breakfasting, or coffee drinking, were related to TTH. Neither stress level or GPA had an association with TTH ( $>>0.05$ ).

Results of the multivariate logistic regression analysis did not differ from the results of the univariate analyses, and the regression coefficients (e $\beta$ ) using the Wald chisquare showed that both gender variable and sleeping hours remained statistically significant in the final regression model $(\mathrm{p}<0.05)$, while all other covariates remained insignificant (Table 4 ).

\section{Aggravating and relieving factors}

The most common aggravating factor for TTH among medical students was studying stressors $(83.3 \%)$, followed by psychological stressors (46.5\%). Additional factors included a decrease in caffeine intake (34.7\%), a decrease in meals $(28.8 \%)$, and a decrease in sleeping hours (10.6\%) (Fig. 2). In order to manage stressors, $70 \%$ of the students reported that they practice relaxation, $30 \%$ spend time with their family and friends, $25 \%$ perform physical exercise, $21 \%$ practice religious rituals and prayers, and $19 \%$ use ventilation techniques (Fig. 3). However, the conventional method to relieve headache was taking analgesic pills (33\%), caffeine (11.6\%), or a combination of both pills and caffeine (15.2\%) (Fig. 4).

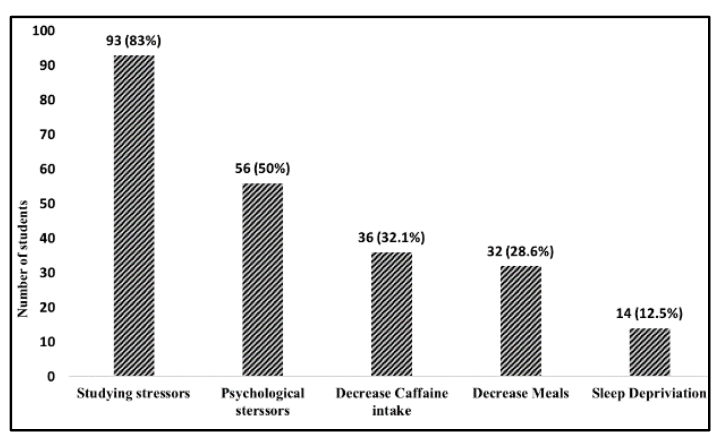

Fig. 2: Aggravating factors for tension-type headache among medical students 


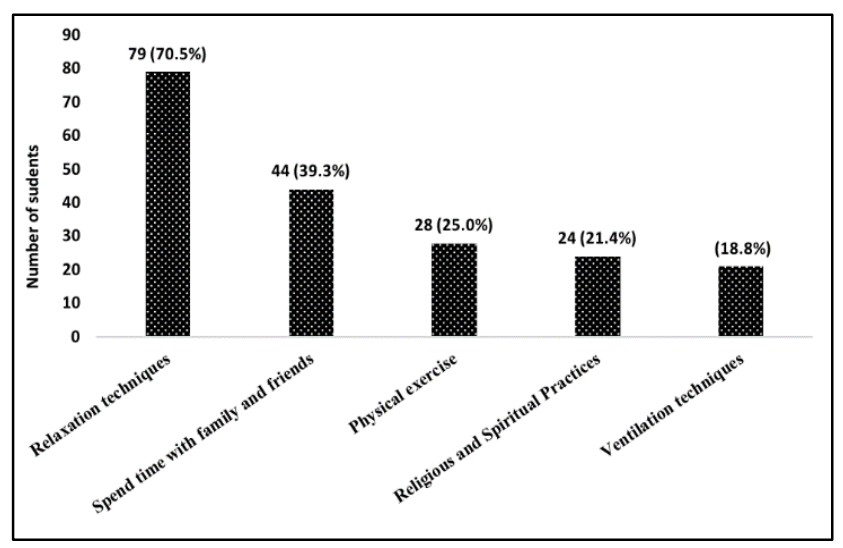

Fig. 3: Methods used by students to manage their stressors

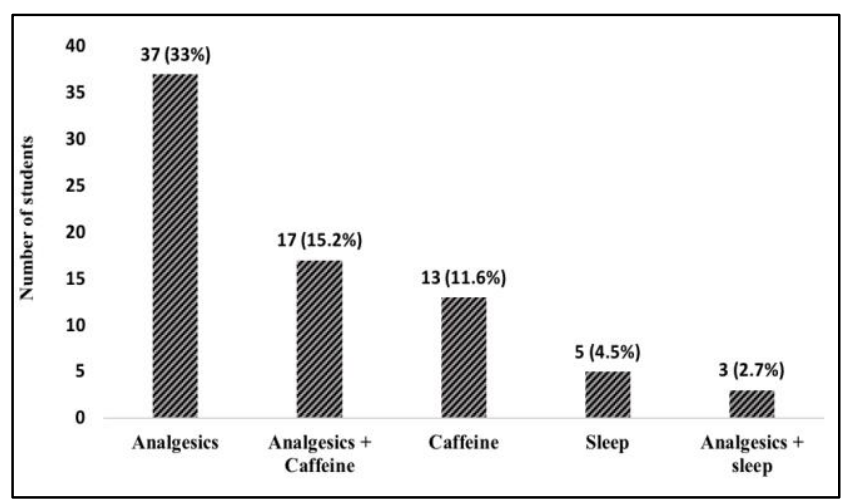

Fig. 4: Methods used by students to manage their headaches

Table 1: Demographic characteristics of medical students $(\mathrm{n}=387)$.

\begin{tabular}{|l|c|c|}
\hline Variable & $\mathbf{N}$ & \% \\
\hline $\begin{array}{l}\text { Age group Mean } \pm \text { SD 22.8 } \\
\text { Maximum=36 }\end{array}$ & \multicolumn{2}{|l|}{ (minimum=20, } \\
\hline$\leqq 22$ & 155 & 40.1 \\
\hline$\geqq 23$ & 232 & 59.9 \\
\hline Gender & & \\
\hline Female & 194 & 50.1 \\
\hline Male & 193 & 49.9 \\
\hline Marital state & & \\
\hline Married & 27 & 7.0 \\
\hline Single & 360 & 93.0 \\
\hline Level of family income & & \\
\hline$>15000$ SR & 209 & 54.0 \\
\hline$>10000$-15000 SR & 89 & 23.0 \\
\hline$\geq 5000-10000$ SR & 58 & 15.0 \\
\hline$<5000$ SR & 31 & 8.0 \\
\hline Educational level & & \\
\hline
\end{tabular}

\begin{tabular}{|l|l|l|}
\hline 4th-year medical student & 151 & 39.0 \\
\hline 5th-year medical student & 132 & 34.1 \\
\hline 6th-year medical student & 104 & 26.9 \\
\hline
\end{tabular}

Table 2: Health-related characteristics of medical students $(\mathrm{n}=387)$.

\begin{tabular}{|c|c|c|}
\hline Variable & $\mathbf{N}$ & $\%$ \\
\hline \multicolumn{3}{|l|}{ level of physical activity } \\
\hline Daily exercise & 74 & 19.1 \\
\hline Occasional & 177 & 45.7 \\
\hline Non & 136 & 35.1 \\
\hline \multicolumn{3}{|l|}{$\begin{array}{l}\text { Have breakfast } \\
\text { morning }\end{array}$} \\
\hline Always & 92 & 23.8 \\
\hline Often & 125 & 32.3 \\
\hline Rarely & 170 & 43.9 \\
\hline \multicolumn{3}{|l|}{ Current smoking } \\
\hline No & 317 & 81.9 \\
\hline Yes & 70 & 18.1 \\
\hline \multicolumn{3}{|l|}{ Coffee drinks } \\
\hline None & 93 & 24.0 \\
\hline One/day & 152 & 39.3 \\
\hline Two/day & 93 & 24.0 \\
\hline$\geq$ three/day & 49 & 12.7 \\
\hline \multicolumn{3}{|l|}{ Energy drinks } \\
\hline None & 357 & 92.2 \\
\hline One/day & 27 & 7.0 \\
\hline Two/day & 3 & .8 \\
\hline \multicolumn{3}{|l|}{ Have sleeping trouble } \\
\hline No & 278 & 71.8 \\
\hline Yes & 109 & 28.2 \\
\hline \multicolumn{3}{|l|}{ Sleeping hours at night } \\
\hline$<8$ hours & 264 & 68.2 \\
\hline$\geq 8$ hours & 123 & 31.8 \\
\hline \multicolumn{3}{|l|}{ Have chronic illness } \\
\hline No & 330 & 85.3 \\
\hline Yes & 57 & 14.7 \\
\hline \multicolumn{3}{|l|}{ Stress level } \\
\hline Sever & 118 & 30.5 \\
\hline Medium & 159 & 41.1 \\
\hline Mild & 110 & 28.4 \\
\hline \multicolumn{3}{|l|}{$\begin{array}{l}\text { Know how to manage } \\
\text { stressors }\end{array}$} \\
\hline No & 128 & 33.1 \\
\hline Yes & 259 & 66.9 \\
\hline
\end{tabular}


Table 3: Bivariate analysis for predictors of tension-type headache among medical students $(\mathrm{n}=387)$

\begin{tabular}{|c|c|c|c|c|c|}
\hline Covariate & TTH* present $(\%)$ & TTH absent (\%) & $\chi^{2}$ & df & P-value \\
\hline Age & & & \multirow[t]{3}{*}{0.90} & \multirow[t]{3}{*}{1} & \multirow[t]{3}{*}{0.343} \\
\hline$<23$ & $49(31.6)$ & $106(68.4)$ & & & \\
\hline$\Rightarrow>23$ & $63(27.2)$ & $169(72.8)$ & & & \\
\hline $\begin{array}{l}\text { Gender } \\
\text { Female } \\
\text { Male }\end{array}$ & $\begin{array}{l}66(34.0) \\
46(23.8)\end{array}$ & $\begin{array}{l}128(66.0) \\
147(76.2)\end{array}$ & 4.88 & 1 & 0.027 \\
\hline $\begin{array}{l}\text { Marital status } \\
\text { Married } \\
\text { Single }\end{array}$ & $\begin{array}{c}8(29.6) \\
104(28.9)\end{array}$ & $\begin{array}{c}19(70.4) \\
256(71.1)\end{array}$ & 0.01 & 1 & 0.935 \\
\hline $\begin{array}{l}\text { Family Income } \\
\leqq 5000 \mathrm{SR} \\
5000-\leqq 10000 \\
1000-15000 \\
\geq 15000\end{array}$ & $\begin{array}{l}8(25.8) \\
14(24.1) \\
32(36.0) \\
58(27.8)\end{array}$ & $\begin{array}{c}23(74.2) \\
44(75.9) \\
57(64.0) \\
151(72.2)\end{array}$ & 3.07 & 3 & 0.381 \\
\hline $\begin{array}{l}\text { Academic level } \\
\text { 4th-year medical student } \\
\text { 5th-year medical student } \\
\text { 6th-year medical student }\end{array}$ & $\begin{array}{l}40(26.5) \\
41(31.1) \\
31(29.8)\end{array}$ & $\begin{array}{l}111(73.5) \\
91(68.9) \\
73(70.2)\end{array}$ & 0.77 & 2 & 0.681 \\
\hline $\begin{array}{l}\text { Physical activity } \\
\text { Daily } \\
\text { Occasional } \\
\text { None }\end{array}$ & $\begin{array}{l}17(23.0) \\
55(31.1) \\
40(29.4)\end{array}$ & $\begin{array}{c}57(77.0) \\
122(68.9) \\
96(70.6)\end{array}$ & 1.69 & 2 & 0.430 \\
\hline $\begin{array}{l}\text { Sleeping trouble } \\
\text { No } \\
\text { Yes }\end{array}$ & $\begin{array}{l}77(27.7) \\
35(32.1)\end{array}$ & $\begin{array}{l}201(72.3) \\
74(67.9)\end{array}$ & 0.74 & 1 & 0.389 \\
\hline $\begin{array}{l}\text { Sleeping hours } \\
<8 \text { hours } \\
\geq 8 \text { hours }\end{array}$ & $\begin{array}{l}89(33.7) \\
23(18.7)\end{array}$ & $\begin{array}{l}175(66.3) \\
100(81.3)\end{array}$ & 9.20 & 1 & 0.002 \\
\hline $\begin{array}{l}\text { chronic illnesses } \\
\text { No } \\
\text { Yes }\end{array}$ & $\begin{array}{l}15(26.3) \\
97(29.4)\end{array}$ & $\begin{array}{c}42(73.7) \\
233(70.6)\end{array}$ & 0.22 & 1 & 0.636 \\
\hline $\begin{array}{l}\text { Smoking status } \\
\text { No } \\
\text { Yes }\end{array}$ & $\begin{array}{l}97(30.6) \\
15(21.4)\end{array}$ & $\begin{array}{c}220(69.4) \\
55(78.6)\end{array}$ & 2.35 & 1 & 0.126 \\
\hline $\begin{array}{l}\text { Have morning breakfast } \\
\text { Regularly } \\
\text { Rarely }\end{array}$ & $\begin{array}{l}57(26.3) \\
55(32.4)\end{array}$ & $\begin{array}{l}160(73.7) \\
115(67.6)\end{array}$ & 1.72 & 1 & 0.190 \\
\hline $\begin{array}{l}\text { Coffee Drinks } \\
\text { No } \\
\text { Yes }\end{array}$ & $\begin{array}{l}25(26.9) \\
87(29.6)\end{array}$ & $\begin{array}{c}68(73.1) \\
207(70.4)\end{array}$ & 0.25 & 1 & 0.615 \\
\hline $\begin{array}{l}\text { Stress Level } \\
\text { Mild } \\
\text { Moderate } \\
\text { High }\end{array}$ & $\begin{array}{l}26(23.6) \\
45(28.3) \\
41(34.7)\end{array}$ & $\begin{array}{c}84(76.4) \\
114(71.7) \\
77(65.3)\end{array}$ & 3.47 & 2 & 0.176 \\
\hline
\end{tabular}




\begin{tabular}{|l|c|c|c|c|c|}
\hline Grade Point Average & $7(20.6)$ & $27(79.4)$ & 4.84 & 3 & 0.184 \\
$<3.5$ & $23(28.0)$ & $59(72.0)$ & & & \\
$3.6-4$ & $41(25.9)$ & $117(74.1)$ & & & \\
$4.1-4.5$ & $41(36.6)$ & $72(63.7)$ & & & \\
$4.6-5$ & & & & & \\
\hline
\end{tabular}

*TTH= Tension-type headache

Table 4: Multiple logistic regression analysis for tension-type headache among medical students $(n=387)$

\begin{tabular}{|l|c|c|c|c|c|c|c|}
\hline Predictors for TTH & $\boldsymbol{\beta}$ & SE $\boldsymbol{\beta}$ & Wald's $\chi^{\mathbf{2}}$ & $\mathbf{d f}$ & $\mathbf{P}$ & $\begin{array}{c}\text { e } \boldsymbol{\beta} \\
\text { OR }\end{array}$ & $\mathbf{9 5 \%}$ CI \\
\hline Constant & -0.379 & 0.845 & 0.201 & 1 & 0.654 & 0.685 & \\
\hline sex & -0.637 & 0.252 & 6.415 & 1 & 0.011 & 0.529 & $0.323-0.866$ \\
\hline Age group & -0.016 & 0.241 & 0.004 & 1 & 0.947 & 0.984 & $0.614-1.578$ \\
\hline Family income & -0.010 & 0.120 & 0.007 & 1 & 0.935 & 0.990 & $0.783-1.252$ \\
\hline Having chronic illness & -0.093 & 0.344 & 0.073 & 1 & 0.788 & 0.911 & $0.465-1.788$ \\
\hline Have morning breakfast & 0.445 & 0.249 & 3.202 & 1 & 0.074 & 1.560 & $0.958-2.540$ \\
\hline Perform Physical exercise & 0.005 & 0.170 & 0.001 & 1 & 0.975 & 1.005 & $0.721-1.402$ \\
\hline Stress level & 0.168 & 0.157 & 1.135 & 1 & 0.287 & 1.183 & $0.869-1.610$ \\
\hline Sleeping hours & -0.900 & 0.278 & 10.480 & 1 & 0.001 & 0.407 & $0.236-0.701$ \\
\hline Test & & & $\chi 2$ & df & P & & \\
\hline Overall model evaluation & & & & & & & \\
\hline Likelihood ratio test & & & 21.677 & 8 & 0.006 & & \\
\hline Score test & & & 20.67 & 8 & 0.008 & & \\
\hline Wald test & & & 64.22 & 1 & 0.000 & & \\
\hline Goodness-of-fit test & & & & & & & \\
\hline Hosmer \& Lemeshow & & & 7.278 & 8 & 0.507 & & \\
\hline
\end{tabular}

\section{Discussion}

The particular purpose of the current study was to determine the prevalence of TTH; by using a validated and structured diagnostic tool for collecting the data, we increased the reliability and power of the study. Besides, we used a tightened diagnostic criterion for TTH, by applying all criteria for diagnosing chronic and episodic TTH, in particular the exclusion of symptoms associated with migraine (nausea or vomiting; and photophobia and phonophobia). Thus, we eliminated migraines, the next common type of primary headache.

The lifetime prevalence of TTH among our subjects (43\%) was similar to many studies, including the global TTH prevalence (all ages) in the Straube and Andreou 2019 review. ${ }^{7,8,14}$ The 1-year prevalence of TTH (28.9\%) was also consistent with the 1-year prevalence rate of TTH (29.1\%-30.8\%) reported from public surveys in Mongolia and Korea $(19,20)$. However; it was slightly higher than the estimated global mean (20.77\%) reported in 2010 Global Burden of Disease (GBD), ${ }^{21}$ probably because our study subjects are medical schoolers who are at higher risk of suffering from headache, and secondly because the epidemiology of TTH is changing, with noticeable increasing trend over years. ${ }^{2,22}$ Concerning medical students, different rates reported from as low as $18.1 \%$ to as high as $66.81 \%$. This variability attributed in part to the fact that different studies used different criteria and different population groups for diagnosing TTH. ${ }^{23-26}$

There are no consistent reports for the association between stress and TTH in the literature; some studies reported a positive association, ${ }^{27}$ while others did not detect a similar association, ${ }^{10}$ nevertheless; a high percentage of TTH sufferers in the current study referred their headache to either studying or psychological stressors, and it seems that they preferred to manage their stressors by natural methods to alleviate their headaches rather than to use medications. In this study, a higher proportion of students with GPA > 4.5 complained from TTH, and This signifies that headache is probably not 
reducing GPA by disturbing studying; on the contrary, hard-working and diligence are provoking TTH.

In the multivariate analysis, female students and students with lower sleeping hours had significantly higher rates of TTH, and these results support the previous studies that reported an association between TTH and female sex and sleep disorders. ${ }^{28,29}$ Unlike other studies, there was no difference in our study concerning the performance of physical exercise among TTH free and TTH sufferers. ${ }^{30}$ The effect of age on TTH was hard to assess among students as they were close in age.

\section{Limitations}

A limitation of this study is the cross-sectional design, which does not provide evidence of the temporal relationship between exposure and outcome, and apart from gender as a causative variable for TTH, only with a longitudinal design, it is possible to establish a causeeffect relationship between TTH and other variables. In spite that this study conducted at one college in Jeddah city, we expect larger generalizability of the results considering that KAU represented the largest public university in the region and being a target for medical students from many villages and territories in the region. Besides, given that the prevalence results are consistent with the knowledge of the existing literature, we expect high validity and reliability of the current study.

\section{Conclusion}

Tension-type headache is a common problem among medical students, and stress-free study environment, stress management courses, and relaxation programs are highly recommended.

\section{Source of Funding}

None.

\section{Conflict of Interest}

None.

\section{References}

1. Stovner LJ, Nichols E, Steiner TJ, Abd-Allah F, Abdelalim A, Al-Raddadi RM, et al. Global, regional, and national burden of migraine and tension-type headache, 1990-2016: a systematic analysis for the global burden of disease study 2016. Lancet Neurol. 2018;17(11):954-76.

2. WHO. Headache disorders [Internet]. World Health Organization, Geneva. 2016 [cited 2020 Feb 1]. Available from: https://www.who.int/news-room/fact- sheets/detail/headache-disorders

3. Hainer BL, Matheson EM. Approach to acute headache in adults. Am Fam Physician. 2013;87(10):682-7.

4. Vosoughi K, Stovner LJ, Steiner TJ, Moradi-Lakeh M, Fereshtehnejad SM, Farzadfar F, et al. The burden of headache disorders in the Eastern Mediterranean Region, 1990-2016: Findings from the global burden of disease study 2016. J Headache Pain [Internet]. 2019;20(1).

5. Stovner LJ, Hagen K, Jensen R, Katsarava Z, Lipton RB, Scher AI, et al. The global burden of headache: A documentation of headache prevalence and disability worldwide. Cephalalgia. 2007;27(3):193-210.

6. The World Health Report 2001: Mental Health: New Understanding, New Hope - World Health Organization Google Books [Internet]. [cited 2019 Dec 13]. Available from: https://books.google.com.sa/books?id=GQEdAVFSIgC\&lpg=PR9\&ots $=$ d 1 WFUEbdvz\&lr $\& p g=P R 9 \# v=$ on epage \&q\&f=false

7. Rastenytė D, Mickevičienė D, Stovner LJ, Thomas H, Andrée C, Steiner TJ. Prevalence and burden of headache disorders in Lithuania and their public-health and policy implications: a population-based study within the Eurolight Project. J Headache Pain. 2017;18(1):53.

8. Straube A, Andreou A. Primary headaches during lifespan. J Headache Pain. 2019;20(1):35.

9. Chowdhury D. Tension type headache. Ann Indian Acad Neurol. 2012;15(SUPPL.):83-8.

10. E Waldie K, Buckley J. Tension-Type Headache: A LifeCourse Review. J Headache Pain Manag. 2015;01(01):1-9.

11. Ibrahim NK, Alotaibi AK, Alhazmi AM, Alshehri RZ, Saimaldaher RN, Murad MA. Prevalence, predictors and triggers of migraine headache among medical students and interns in. Pak J Med Sci. 2017;33(2):270-5.

12. Semiz M, Şentürk IA, Balaban H, Yağiz AK, Kavakçi Ö. Prevalence of migraine and co-morbid psychiatric disorders among students of Cumhuriyet University. J Headache Pain. 2013;14(1):34.

13. Vincent M, Wang S. Headache Classification Committee of the International Headache Society (IHS) The International Classification of Headache Disorders, 3rd edition. Cephalalgia. 2018;38(1):1-211.

14. Ghorbani A, Abtahi SM, Fereidan-Esfahani M, Abtahi SH, Shemshaki H, Akbari M, et al. Prevalence and clinical characteristics of headache among medical students, Isfahan, Iran. J Res Med Sci. 2013;18(SPL. 1):8-15.

15. Almesned I, Alqahtani N, Alarifi J, Alsaawy T, Agha S, Alhumaid M. Prevalence of primary headache among medical students at King Saud bin Abdulaziz University for Health Sciences, Riyadh, Saudi Arabia. J Fam Med Prim Care. 2018;7(6):1193.

16. Gu X, Xie YJ. Migraine attacks among medical students in Soochow university, southeast China: A cross-sectional study. J Pain Res. 2018;11:771-81.

17. Elrington G. Migraine: Diagnosis and management. J Neurol Neurosurg \&amp;amp; Psychiatry [Internet]. 2002;72(suppl 2):ii10 LP-ii15. 
18. Song TJ, Cho SJ, Kim WJ, Yang KI, Yun CH, Chu MK. Anxiety and depression in tension-type headache: A population-based study. PLoS One. 2016;11(10):1-12.

19. Kim BK, Chu MK, Lee TG, Kim JM, Chung CS, Lee KS. Prevalence and impact of migraine and tension-type headache in Korea. J Clin Neurol. 2012;8(3):204-11.

20. Luvsannorov O, Tsenddorj B, Baldorj D, Enkhtuya S, Purev D, Thomas H, et al. Primary headache disorders among the adult population of Mongolia: Prevalences and associations from a population-based survey. $J$ Headache Pain. 2019;20(1).

21. Reinhart L, Knight W, Roberts L, Mendes C. HHS Public Access Global Burden of Disease Study 2010. Lancet. 2012;380(9859):2163-96.

22. Monzani L, Zurriaga R, López GVE. Anxiety and the severity of tension-type headache mediate the relation between headache presenteeism and workers' productivity. PLoS One. 2018;13(7):1-11.

23. Ojini FI, Okubadejo NU, Danesi MA. Prevalence and clinical characteristics of headache in medical students of the University of Lagos, Nigeria. Cephalalgia [Internet]. 2009;29(4):472-7.

24. Birru EM, Abay Z, Abdelwuhab M, Basazn A, Sirak B, Teni FS. Management of headache and associated factors among undergraduate medicine and health science students of University of Gondar, North West Ethiopia. J Headache Pain. 2016;17(1). Available from:

http://dx.doi.org/10.1186/s10194-016-0647-4
25. Kurt S, Kaplan Y. Epidemiological and clinical characteristics of headache in university students. Clin Neurol Neurosurg. 2008;110(1):46-50.

26. Hatem AK, Al-Johar ZA, Idrees RAJ, Khalaf MA, Shawket WA. The prevalence of tension type headache among students of Baghdad college of medicine in 2018. Indian J Public Heal Res Dev. 2019;10(10):837-41.

27. Waldie KE. Childhood headache, stress in adolescence, and primary headache in young adulthood: A longitudinal cohort study. Headache. 2001;41(1):1-10.

28. Delaruelle Z, Ivanova TA, Khan S, Negro A, Ornello R, Raffaelli B, et al. Male and female sex hormones in primary headaches. J Headache Pain. 2018;19(1):1-12.

29. Kim J, Cho SJ, Kim WJ, Yang KI, Yun CH, Chu MK. Insomnia in tension-type headache: A population-based study. J Headache Pain. 2017;18(1):95.

30. Sertel M, Bakar Y, Şimşek TT. The effect of body awareness therapy and aerobic exercises on pain and quality of life in the patients with tension type headache. Afr J Tradit Complement Altern Med. 2017;14(2):288-310.

How to cite this article: Qutub WN, Magharbel RS, Adham SW, Bardisi WM, NA Akbar. Prevalence and determinants of tension headache among medical students during their clinical years at King Abdulaziz University in Jeddah, 2019. J Community Health Manag. 2020;7(1):14-21. 